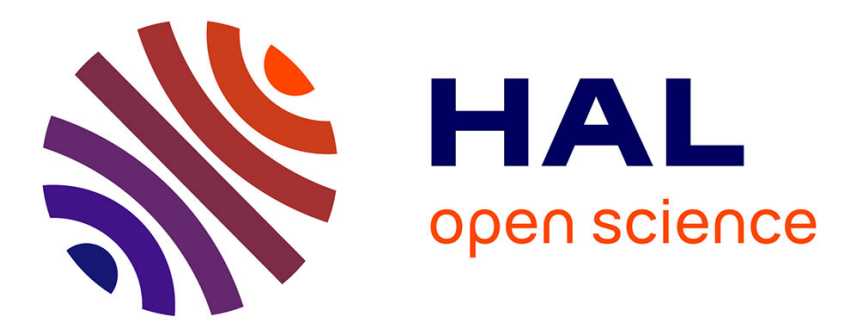

\title{
The China Clipper - fast advective transport of radon-rich air from the Asian boundary layer to the upper troposphere near California
}

\author{
Mark A Kritz, Jean-Claude Le Roulley, Edwin F Danielsen
}

\section{To cite this version:}

Mark A Kritz, Jean-Claude Le Roulley, Edwin F Danielsen. The China Clipper - fast advective transport of radon-rich air from the Asian boundary layer to the upper troposphere near California. Tellus B - Chemical and Physical Meteorology, 1990, 42 (1), pp.46 - 61. 10.3402/tellusb.v42i1.15191. hal-03582121

\author{
HAL Id: hal-03582121 \\ https://hal.science/hal-03582121
}

Submitted on 21 Feb 2022

HAL is a multi-disciplinary open access archive for the deposit and dissemination of scientific research documents, whether they are published or not. The documents may come from teaching and research institutions in France or abroad, or from public or private research centers.
L'archive ouverte pluridisciplinaire HAL, est destinée au dépôt et à la diffusion de documents scientifiques de niveau recherche, publiés ou non, émanant des établissements d'enseignement et de recherche français ou étrangers, des laboratoires publics ou privés. 


\title{
The China Clipper - fast advective transport of radon-rich air from the Asian boundary layer to the upper troposphere near California
}

\author{
Mark A. Kritz, Jean-Claude Le Roulley \& Edwin F. Danielsen
}

To cite this article: Mark A. Kritz, Jean-Claude Le Roulley \& Edwin F. Danielsen (1990) The China Clipper - fast advective transport of radon-rich air from the Asian boundary layer to the upper troposphere near California, Tellus B: Chemical and Physical Meteorology, 42:1, 46-61, DOI: 10.3402/tellusb.v42i1.15191

To link to this article: https://doi.org/10.3402/tellusb.v42i1.15191

$$
\begin{aligned}
& \text { (c) } 1990 \text { The Author(s). Published by Taylor \& } \\
& \text { Francis. }
\end{aligned}
$$

曲 Published online: 18 Jan 2017.

Submit your article to this journal 지

Џ Article views: 30

Q View related articles $\asymp$

Citing articles: 1 View citing articles 


\title{
The China Clipper-fast advective transport of radon-rich air from the Asian boundary layer to the upper troposphere near California
}

\author{
By MARK A. KRITZ, Atmospheric Sciences Research Center, State University of New York, \\ Albany, NY 12222, USA, JEAN-CLAUDE LE ROULLEY, Centre des Faibles Radioactivities, \\ Domaine du CNRS, 91190 Gif-sur-Yvette, France and EDWIN F. DANIELSEN, \\ Space Science Division, NASA Ames Research Center, Moffett Field, CA 94035, USA
}

(Manuscript received 1 November 1988; in final form 5 June 1989)

\begin{abstract}
A series of upper tropospheric radon concentration measurements made over the eastern Pacific and west coast of the United States during the summers of 1983 and 1984 has revealed the occurrence of unexpectedly high $[>16 \mathrm{pCi} / \mathrm{SCM}]$ radon concentrations for 9 of the 61 measurements (and 6 of the 13 flights). A frequency distribution plot of the set of 61 observations shows a distinct bimodal distribution, with approximately $\frac{2}{5}$ of the observations falling close to $1 \mathrm{pCi} / \mathrm{SCM}$, and $\frac{3}{5}$ falling in a high concentration mode centered at about $11 \mathrm{pCi} / \mathrm{SCM}$. Trajectory and synoptic analyses for two of the flights on which such high radon concentrations were observed indicate that this radon-rich air originated in the Asian boundary layer, ascended in cumulus updrafts, and was carried eastward in the fast moving air on the anti-cyclonic side of the upper tropospheric jet. Transit times were of the order of 3 days; however, in one instance, transport from China to a point a few hundred kilometers west of San Francisco occurred in $48 \mathrm{~h}$. These findings suggest that the combination of rapid vertical transport from the surface boundary layer to the upper troposphere, followed by rapid horizontal transport eastward represents an efficient mode of long-transport for other, chemically reactive atmospheric trace constituents.
\end{abstract}

\section{Introduction}

Radon $\left({ }^{222} \mathrm{Rn}\right)$ enters the atmosphere from the crust, where it is produced by the radioactive decay of its parent, ${ }^{226} \mathrm{Ra}$. Because radon is a noble gas, and relatively insoluble in water, its removal from the atmosphere by precipitation scavenging is negligible, so that its only significant atmospheric sink is its own radioactive decay, which occurs with a half-life of 3.8 days. For these reasons atmospheric radon measurements have been used as an indicator of vertical transport (e.g., Jacobi and Andre, 1963; Larson, 1973; Liu et al., 1984), as well as an indicator of the presence and transport of continental air over the oceans (e.g., Prospero and Carlson, 1970; Larson et al., 1972; Wilkness et al., 1973; Polian et al., 1986; Andreae et al., 1988). However while numerous observations have been made of radonrich continental air over the oceans, those reported here are remarkable because of the distance, speed and altitude of the associated transports.

The highest concentrations of atmospheric radon occur in the continental boundary layer, where values on the order of $100-300 \mathrm{pCi} / \mathrm{SCM}$ (standard cubic meter) are frequently observed (Gold et al., 1964; Cox et al., 1970; Lambert et al., 1982). Radon concentrations in the free troposphere are typically an order of magnitude or more lower, decreasing, in the mean, with altitude to values on the order of 1 or $2 \mathrm{pCi} / \mathrm{SCM}$ near the tropopause (Wexler et al., 1956; Wilkening, 1970; Moore et al., 1973; Liu et al., 1984.)

The decrease of mean concentration with alti- 
tude is consistent with that which would arise from simple vertical mixing, and diffusion-based parameterizations have frequently been used to model radon concentration profiles. For example, Liu et al. (1984) compiled published radon profiles and derived a seasonal altitude dependent vertical mixing coefficient which they used to estimate the rate of vertical transport of other, chemically active, trace constituents. There is, however, a growing awareness of the important role of fast, localized advection in the vertical distribution of many atmospheric trace constituents, as discussed by Kritz (1975), Gidel (1983), Dickerson et al. (1987) and others, as well as by Liu et al. (1984) in their analysis.

In this work we present the results of a series of 61 upper tropospheric radon concentration measurements made aboard a NASA C-141 aircraft flying over the eastern Pacific and west coast of North America. These observations were made during the summers of 1983 and 1984, at altitudes ranging from 11.3 to $12.5 \mathrm{~km}(37,000$ to 41,000 feet). Radon concentrations greater than $16 \mathrm{pCi} / \mathrm{SCM}$ were observed on 6 of the 13 flights made during this period, and in 9 of the 61 individual measurements. In order to understand the cause of these high concentrations the flights of 28 July and 31 July 1983 were selected for detailed examination.

\section{Instrumentation}

The measurements reported here were made using the active daughter technique. The decay of radon leads to the formation of a series of shortlived daughters, as shown in the simplified radon decay chain below.

$$
\begin{aligned}
& { }^{222} \mathrm{Rn} \quad \rightarrow \quad{ }^{218} \mathrm{Po} \quad \rightarrow \quad{ }^{214} \mathrm{~Pb} \\
& \text { (3.8 days) (3.05 minutes) (26.8 minutes) } \\
& \rightarrow \quad{ }^{214} \mathrm{Bi} \rightarrow{ }^{214} \mathrm{Po} \rightarrow{ }^{210} \mathrm{~Pb} \\
& \text { (19.7 minutes) (<0.01 s) (22 years) }
\end{aligned}
$$

While radon is a noble gas, all of its daughters are metals, which upon formation are quickly and irreversibly scavenged by particles of the ambient aerosol. Because their lifetimes are short relative to that of radon and the particles to which they are attached, the short-lived radon daughters are in secular equilibrium with their parent and with one another, so that accurate determinations of atmospheric radon concen- trations can be made by measuring the concentration of one (or several) of the short-lived daughters (Gold et al., 1964; Larson, 1973; Polian, 1984).

Measurement of atmospheric radon concentrations using the active daughter method is a two stage process. In the first stage, or sampling period, ambient aerosols (to which the radon daughters are attached) are collected on a filter. In the second stage, or counting period, the alpha (or beta) activity of the aerosols collected on the filter is measured. Because the half-lives of the short-lived daughters are less than $30 \mathrm{~min}$, this counting must be done shortly after sample collection. The ambient radon concentration is computed using the following formula:

$[\mathrm{Rn}]=K_{1} C_{t} / \phi \eta f\left(T_{s}, T_{\mathrm{d}}, T_{\mathrm{c}}\right)$

where $[\mathrm{Rn}]$ is the ambient radon concentration in picoCuries (pCi) per SCM; $K_{1}$ is a constant; $C_{t}$ the net number of counts recorded during the counting period (total number less background); $\phi$ the sampling flowrate; $\eta$ is the system efficiency; and $f\left(T_{\mathrm{s}}, T_{\mathrm{d}}, T_{\mathrm{c}}\right)$ is a function of $T_{\mathrm{s}}$, the length of the sampling period, $T_{\mathrm{d}}$, the length of time between the end of the sampling period and the beginning of the counting period, and $T_{\mathrm{c}}$, the length of the counting period. This formulation, and the calculation of $f\left(T_{\mathrm{s}}, T_{\mathrm{d}}, T_{\mathrm{c}}\right)$ is similar to and derived from those developed by Evans (1955); Larson (1973); Polian (1984) and others.

The precision, accuracy and sensitivity of the active daughter technique depend upon close attention to several critical factors. For the present study, these were assurance of isokinetic sampling of free stream air, freedom from interferences from other atmospheric radionuclides, and knowledge and control of the detector background count rate and system efficiency. These points are addressed in the description of the instrumentation and operating procedures.

\subsection{Sample collection system}

This consisted of the aerosol collection probe, filter holder, flowmeter, in-line pressure and temperature sensors, a variable speed pump, and the pump control/sampling monitoring unit. The aerosol collection probe was mounted in the right hand forward door of the aircraft, replacing a window and extending $40 \mathrm{~cm}$ from the fuselage. 
In-flight tests were conducted to ensure that the inlet was in free stream air and aligned parallel to the local airflow.

Aerosol particles were collected on $12.5 \mathrm{~cm}$ diameter Whatman 41 filters. The sampling flowrate was adjusted by varying the pump speed to give isokinetic conditions at the aerosol inlet, as calculated from aircraft speed and the outside pressure and temperature. The nominal sampling period was $30 \mathrm{~min}$, though this varied in individual cases from 15 to $60 \mathrm{~min}$.

\subsection{Detector/counter system}

Following their exposure to the ambient air, the filters were placed under a $12 \mathrm{~cm}$ diameter $\mathrm{ZnS}$ scintillator sensitive to the 6.0 and $7.7 \mathrm{MeV}$ alpha particles emitted by ${ }^{218} \mathrm{Po}$ and ${ }^{214} \mathrm{Po}$. A conical lightguide was used to interface the scintillator with a $5 \mathrm{~cm}$ diameter photo multiplier tube (PMT). A $5 \mathrm{~cm}$ thick annular plastic scintillator surrounded this $\mathrm{ZnS}$ scintillator assembly, and served as an anticoincidence guard. The signal outputs of the detector and the guard PMTs passed through preamplifiers and connected to a gating circuit which blocked those pulses from the detector PMT which were coincident with pulses from the guard PMTs.

Because of the increase of cosmic ray flux with altitude, background count rates of unguarded detectors increase rapidly with aircraft altitude (e.g., Jegou, 1983; Wilkness and Larson, 1984). (Use of guard circuits is generally unnecessary in laboratory alpha counting systems since cosmic ray fluxes are relatively low at ground levels.)

The detector background count rate was controlled in 3 ways. First, alpha rather than beta emissions from the short-lived radon daughters were counted, as it has been found (e.g., Jegou, 1983) that alpha detection systems are inherently less sensitive to cosmic ray interference at the altitudes of interest in the present study. Second, an anticoincidence guard circuit was used, as described above. Third, the detector output pulses were recorded by a multi-channel analyzer. Although the resultant pulse amplitude distribution spectra are not to be confused with alpha energy spectra, use of the analyzer in this manner allowed us to monitor detector performance more closely, and to discriminate between electronic noise pulses, which tend to be confined to the lower channels, and alpha pulses, which regis- tered in the middle and upper channels. While such spurious counts could, in principle, be eliminated by the use of upper and lower level discriminators, in practice it was found that the optimum upper and lower limits for the signal window varied with aircraft altitude, so that use of the analyzer assured an optimum signal-tonoise ratio for the high altitude radon measurements.

In flight, at altitudes of $10-12 \mathrm{~km}$, the background count rate of the detector was typically 0.5 counts $/ \mathrm{min}$. This rate was more than adequate for the present study, as many of the radon concentrations reported here gave rise to count rates on the order of 10 to 20 counts $/ \mathrm{min}$. Background checks and standard source calibrations were routinely performed during the flights, as described below.

\subsection{Operational procedures}

On a typical flight exposure of the first filter sample began shortly after levelling off at the first flight altitude, which was usually $11.3 \mathrm{~km}(37,000$ feet.) During this first sampling period an initial series of background and calibration counts was run on the detector/counting system. At the end of its sampling period, the exposed filter was removed from the sampling system and placed under the detector.

Filters were typically exposed for $30 \mathrm{~min}$, and counted for an approximately equal length of time. This counting period was subdivided into two or more intervals; for example, a 30-min counting period would be subdivided into either 2 successive 15 -min counting periods, or 3 successive 10-min counting periods. Subdividing the counting period in this manner was an important part of the measurement procedure; the activity of the short-lived radon daughters collected on the filters decays at a known rate, so that the observation of the expected decrease in activity from one counting period to the next is a good confirmation that the counts being recorded are due to radon daughters, and not to a sudden increase in background noise, or the presence of other, longer-lived radionuclides.

A separate radon concentration calculation was made (using eq. (1)) for each of the counting periods, and one of the criteria for accepting each of the radon concentration measurements reported here was good agreement (allowing for 
statistical uncertainty) between the concentrations calculated for each subdivision of the counting period.

As a further check, selected filters were recounted following a flight, to verify that there was no residual activity from long-lived radionuclides. (The activity of the short-lived radon daughters would decay away in a few hours). No such residual activity was ever observed.

Between 3 and 7 samples were collected and analyzed per flight, as dictated by the number of background counts and calibrations, the scheduling of other tests and evaluations, and the duration of the flight itself.

Our normal procedure called for at least 4 15 -min background counts to be made during each flight, at intervals of $60 \mathrm{~min}$. In addition, periodic in-flight checks on detector performance were made with an ${ }^{241} \mathrm{Am}$ standard. The same standard was used for all the results reported here, assuring consistency between the various flights and flight series. Finally, the absolute calibration of the system (which included the trapping efficiency of the filters as well as the counting efficiency of the detector) was verified by measuring the gaseous radon content of several whole air samples, which were collected simultaneously with filter samples and subsequently analyzed in a laboratory system similar to that used by Broecker and Peng (1971).

On the basis of the tests described above, and the uncertainties in the flowrate measurement, background count rate and detector efficiency, the uncertainty of the radon measurement is estimated to be $\pm 15 \%$ for concentrations greater than $7 \mathrm{pCi} / \mathrm{SCM}$, and $\pm 1 \mathrm{pCi} / \mathrm{SCM}$ for lower concentrations.

\section{Results}

A total of 61 radon concentration measurements were made during the course of 13 flights during the summers of 1983 and 1984. The flights were made over the eastern Pacific Ocean, and over the west coast of North America. Samples were collected at altitudes ranging from 11.3 to $12.5 \mathrm{~km}$. The radon concentrations determined during these flights are tabulated in Table 1.

As mentioned earlier, radon concentrations in excess of $16 \mathrm{pCi} / \mathrm{SCM}$ were observed in 9 of the 61 measurements, and during 6 of the 13 flights.
This value is more than five times greater than the 1-2 $\mathrm{pCi} / \mathrm{SCM}$ concentrations thought typical of this region of the atmosphere.

In order to understand the origin of this radonrich air, two flights made during the course of a deployment of the aircraft to Oahu, Hawaii were selected for trajectory analyses. These flights are discussed below.

28 July 1983. This flight was made to the northwest of Hawaii. Takeoff was at 0620 GMT (8:20 p.m. local time). Fig. 1 shows the flight path of the aircraft, and the location and value of each of the seven radon measurements made during the flight. These concentrations are also tabulated in Table 1. Aircraft altitude was $11.3 \mathrm{~km}$ for the first sample, $11.9 \mathrm{~km}$ for the second, and $12.5 \mathrm{~km}$ for the balance of the flight. At $23^{\circ} \mathrm{N} 168^{\circ} \mathrm{W}$ some isolated high cumulus and lightning was observed north of and well below the level of the aircraft.

31 July 1983. This was the return flight to Moffett Field. Takeoff was at 1924 GMT (9:24 a.m. local time). Cruising altitude during the flight was $11.6 \mathrm{~km}$. The flight path of the aircraft on this date is plotted in Fig. 2, together with the location and concentration of each of the radon measurements made during the flight. These concentrations, together with the time, altitude and location of each sample also appear in Table 1. Scattered fair weather cumulus were observed at low altitude throughout the flight.

\section{Meteorological analysis}

The probable source regions for the air masses sampled during the 28 and 31 July flights were determined by constructing trajectories from consecutive 12-h analyses of the Montgomery stream function, $\psi_{m}$, on a constant potential temperature $(\theta)$ surface. The sum of potential energy and enthalpy per unit mass,

$\psi_{m}=\left(g z+C_{\mathrm{p}} T\right)_{\theta}$,

where $g$ is the acceleration of gravity, $C_{\mathrm{p}}$ the specific heat at constant pressure, and the height $z$ and temperature $T$ refer to a constant $\theta$ surface. Values of $\psi_{m}$ at constant $\theta$ are computed from radiosonde observations and plotted by machine. To obtain the accuracy required for contour analysis, $Z_{\theta}$ and $T_{\theta}$ must not be determined 
Table 1. Summary of radon concentration measurements

\begin{tabular}{|c|c|c|c|c|c|c|c|}
\hline Date & $\begin{array}{l}\text { Time } \\
(\mathrm{GMT})\end{array}$ & $\begin{array}{l}\text { Altitude } \\
(\mathrm{km})\end{array}$ & $\begin{array}{l}\text { [Radon] } \\
(\mathrm{pCi} / \mathrm{SCM})\end{array}$ & Date & $\begin{array}{l}\text { Time } \\
\text { (GMT) }\end{array}$ & $\begin{array}{l}\text { Altitude } \\
(\mathrm{km})\end{array}$ & $\begin{array}{l}\text { [Radon] } \\
(\mathrm{pCi} / \mathrm{SCM})\end{array}$ \\
\hline \multirow[t]{4}{*}{14 July 1983} & 0516 & 11.6 & 1 & \multirow[t]{4}{*}{10 August 1983} & 0528 & 11.3 & $<1$ \\
\hline & 0604 & 12.2 & 1.2 & & 0620 & 11.9 & 19 \\
\hline & 0701 & 12.5 & $<1$ & & 0713 & 12.5 & 1.2 \\
\hline & & & & & 1001 & 12.5 & 11 \\
\hline \multirow[t]{6}{*}{19 July 1983} & 0357 & 11.3 & 5.5 & & 1100 & 12.5 & 1.9 \\
\hline & 0436 & 12.5 & 6.5 & & & & \\
\hline & 0521 & 12.5 & 2.2 & 7 June 1984 & 0727 & 11.3 & 4.1 \\
\hline & 0736 & 12.5 & $<1$ & & 0830 & 11.9 & 11 \\
\hline & 0814 & 12.5 & $<1$ & & 0955 & 12.5 & 10 \\
\hline & & & & & 1106 & 12.5 & 9 \\
\hline \multirow{4}{*}{22 July 1983} & 0500 & 12.5 & $<1$ & & 1252 & 12.5 & 9 \\
\hline & 0720 & 12.5 & $<1$ & & 1302 & 12.5 & 7.5 \\
\hline & 0822 & 12.5 & 1.2 & & & & \\
\hline & & & & 11 July 1984 & 0353 & 11.3 & 3.2 \\
\hline \multirow[t]{4}{*}{26 July 1983} & 0405 & 9.4 & 20 & & 0534 & 11.9 & $<1$ \\
\hline & 0508 & 11.9 & 5 & & 0716 & 12.5 & $<1$ \\
\hline & 0810 & 12.5 & 8.2 & & & & \\
\hline & & & & 17 July 1984 & 0312 & 11.3 & 9 \\
\hline \multirow[t]{8}{*}{28 July 1983} & 0702 & 11.3 & 3.8 & & 0412 & 11.9 & 3.5 \\
\hline & 0741 & 11.9 & 26 & & 0446 & 12.5 & $<1$ \\
\hline & 0814 & 12.5 & 7.5 & & 0540 & 12.5 & $<1$ \\
\hline & 0850 & 12.5 & 1.9 & & 0643 & 12.5 & 1.9 \\
\hline & 1007 & 12.5 & 6 & & & & \\
\hline & 1111 & 12.5 & 3.5 & 20 July 1984 & 0536 & 10.7 & 29 \\
\hline & 1225 & 12.5 & 40 & & 0634 & 12.5 & 31 \\
\hline & & & & & 0735 & 12.5 & 16 \\
\hline \multirow[t]{7}{*}{30 July 1983} & 0718 & 11.9 & 18 & & 0831 & 12.5 & 8.2 \\
\hline & 0756 & 11.9 & 9 & & 0932 & 12.5 & 7.5 \\
\hline & 0833 & 11.9 & $<1$ & & 1046 & 12.5 & 23 \\
\hline & 0939 & 11.9 & 3.8 & & & & \\
\hline & 1052 & 12.5 & 3.8 & 24 July 1984 & 0521 & 11.9 & 1.2 \\
\hline & 1220 & 12.5 & 8.2 & & 0616 & 12.5 & $<1$ \\
\hline & & & & & 0717 & 12.5 & $<1$ \\
\hline \multirow[t]{4}{*}{31 July 1983} & 1958 & 11.6 & $<1$ & & 0813 & 12.5 & $<1$ \\
\hline & 2130 & 11.6 & 11 & & 0908 & 12.5 & $<1$ \\
\hline & 2212 & 11.6 & 14 & & & & \\
\hline & 2251 & 11.6 & 16 & & & & \\
\hline
\end{tabular}

independently. Sufficient accuracy is achieved if the $P_{\theta}$ used to compute $Z_{\theta}$ from the hydrostatic equation is also used to compute $T_{\theta}$ from the adiabatic form of the energy equation defining $\theta$ (Danielsen, 1959):

$\theta=T\left(\frac{1000}{p}\right)^{0.286}$.

The horizontal gradient of $\psi_{m}$ at constant $\theta$ determines the geostrophic wind (direction and speed):

$f \boldsymbol{V}_{\mathrm{g}}=\boldsymbol{k}_{1} \times \nabla_{\mathrm{H}}\left(\psi_{m}\right)_{\theta}$, where $f$ is the Coriolis parameter, $2 \omega \sin \phi ; \omega$ is the angular speed of the earth; $\phi$ the latitude; $\boldsymbol{k}_{1}$ a unit vertical vector; and $\nabla_{H}$ the horizontal gradient operator.

Trajectories computed under the adiabatic assumption are actually three-dimensional, but (as we are working on $A$ surfaces) the problem of determining successive norizontal positions is reduced to two dimensions. The corresponding vertical positions and mean vertical velocities are evaluated from the appropriate $\theta$ analyses at the successive horizontal positions. (A comparison of 


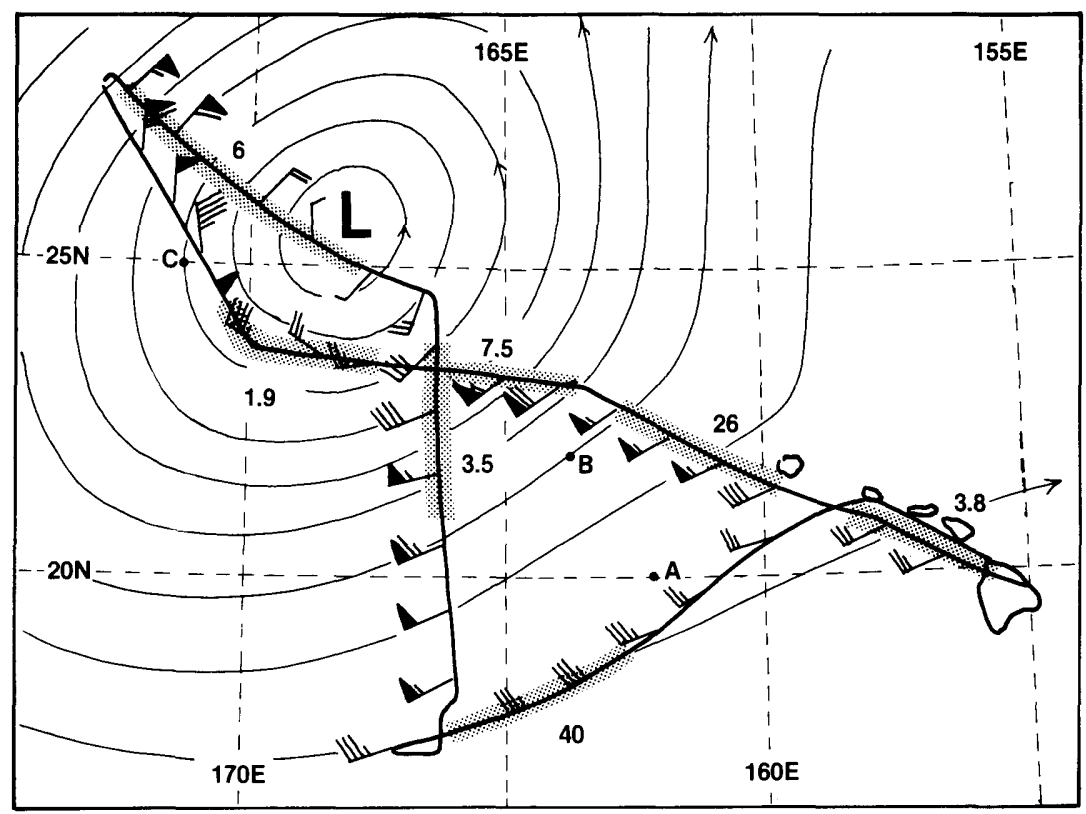

Fig. 1. Aircraft flight path for 28 July 1983.

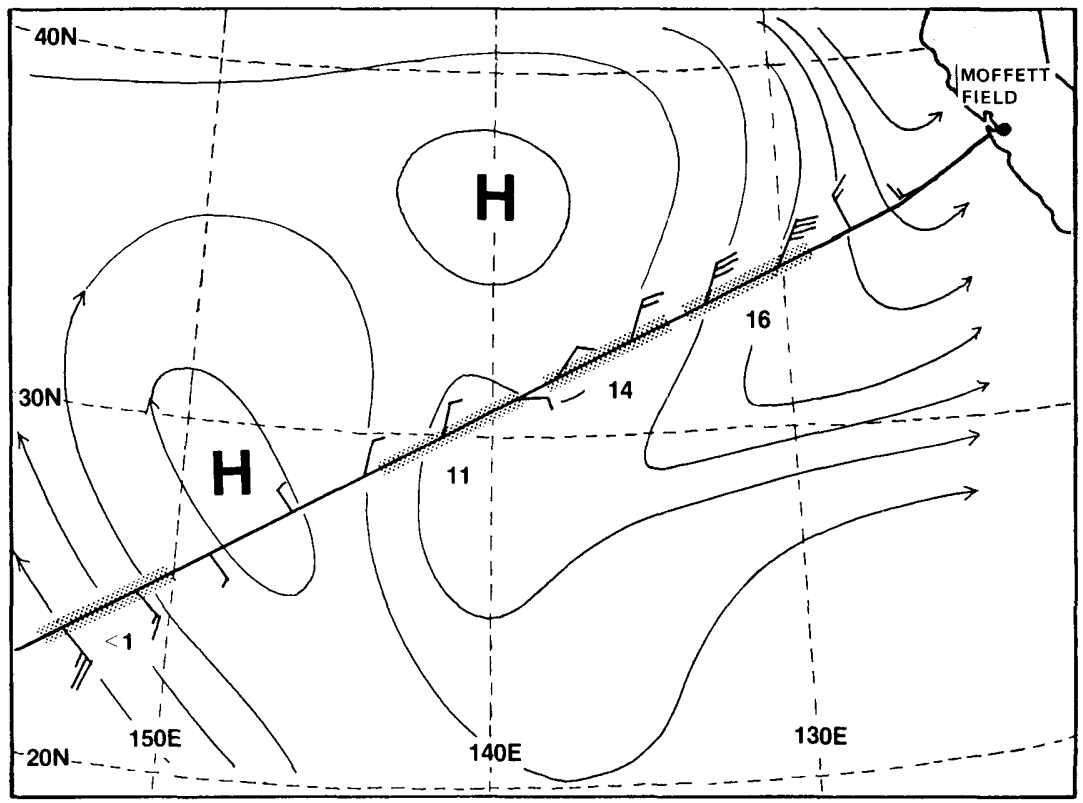

Fig. 2. Aircraft flight path for 31 July 1983.

Tellus 42B (1990), 1 
the adiabatic and isobaric assumptions in trajectory analysis is given in Danielsen, 1961.)

The relative importance of the $\psi_{m}$ and the wind analyses in a given trajectory computation depends upon the density of rawinsonde observations. In data-rich regions the winds are of primary importance and the $\psi_{m}$ analyses subordinate, while in data poor regions like the Pacific Ocean, the winds must be derived iteratively from successive $\psi_{m}$ analyses.

As a first approximation to $V$, eq. (4) is used to determine $\boldsymbol{V}_{\mathrm{g}}$. Then the generalized gradient wind equation

$\frac{V^{2}}{R_{\mathrm{T}}}+f V=f V_{\mathrm{g}} \cos \alpha$,

is used to compute a second approximation to $V$ by setting $\alpha=0$, and $R_{\mathrm{T}}$, the radius of curvature of the trajectory, equal to that of the $\psi_{m}$ isoline. ( $\alpha$ is the angle between $\boldsymbol{V}$ and $\boldsymbol{V}_{\mathrm{g}}$ and is positive when $\boldsymbol{V}$ is to the left of $\boldsymbol{V}_{\mathrm{g}}$.) A 6-h displacement backward in time along the $\psi_{m}$ isoline determines a point on the $t-12 \mathrm{~h}$ map. Another 6-h displacement at the same speed but along the $\psi_{m}$ isoline on that map determines the first approximation to the trajectory.

At the $t-12 \mathrm{~h}$ point eq. (5) is used to evaluate $V$, again assuming $R_{\mathrm{T}}=R \psi_{m}$ at $t-12 \mathrm{~h}$. If $V(t-12 \mathrm{~h})$ differs from $V(t)$, the speed acceleration equation

$\frac{\mathrm{d} V}{\mathrm{~d} t}=f V_{\mathrm{g}} \sin \alpha$

is used to determine a mean value of $\alpha$ for the 12-h interval. The second approximation to the trajectory includes a displacement at a slight angle, $\bar{\alpha}$, to the $\psi_{m}$ isolines. For example, if $V(t) \gg V(t-12 \mathrm{~h})$, the backward displacement crosses the $\psi_{m}$ isoline towards larger values. After a series of successive 12-h positions are established, the points are joined by a smooth curve which then allows $R_{\mathrm{T}}$ to be evaluated for each map. If $R_{\mathrm{T}}$ differs from $R \psi_{m}$ on any map, the entire procedure is repeated with refined curvatures, velocities and displacements until the approximations converge to acceptable limits, i.e., until the left and right sides of eqs. (5) and (6) balance to $\leqslant 10 \%$. If successive approximations diverge, trajectories are computed from a matrix of points to aid in identifying an analysis error. For example, it may be necessary to increase or decrease the $\psi_{m}$ gradients on a given map. One such adjustment was required in the current set of maps. In addition, time continuity charts were constructed following the method of Danielsen (1980), which was developed specifically for use in low data density regions.

To compensate for the low density of radiosonde observations over the Pacific we made extensive use of infrared cloud photographs from the United States and Japanese geostationary satellites, transferring the outlines of cold, upper tropospheric clouds to the corresponding $\theta$ charts. Boundaries of moist and dry air from the $6.7 \mu$ water vapor channel of the United States (GOES) satellite were also transferred to these charts. These boundaries, separating the dry air to the north (or west) from moist air to the south (or east) also delineate the separation between dry stratospheric air and moist upper tropospheric air. By charting the successive positions of these boundaries the location of the jet stream can be established. In general, when the jet undulates the $\psi_{m}$ isolines are curved negatively (anticyclonically) in (moist) tropospheric air and positively (cyclonically) in (dry) stratospheric air. Thus the abrupt change from moist to dry air occurs well in advance of an amplifying trough, where the $\psi_{m}$ curvatures change from negative to positive. The positive curvatures west of the dry boundary form the trough several hundreds of kilometers west of, and parallel to, the dry boundary.

The latter pattern recognition example discussed above is presented, in part, to emphasize the continuity of $\psi_{m}$ analyses where the isopleths cross pattern boundaries. No zero or higher order discontinuities are imposed, so that the boundaries do not define closed subsystems, and mixing across boundaries is recognized as physically possible. Indeed, the boundaries are maintained by the competing action of large scale deformations, which tend to increase gradients, and small scale mixing, which tends to decrease gradients. An example of a strong deformation is discussed later in this section.

Following the procedures outlined above, the trajectories presented in Figs. 3 and 4 were constructed backwards in time from the positions where the radon measurements were made on the 28 July and 30 July flights. However, it is more convenient to discuss them in the opposite sense, i.e., with time increasing. 


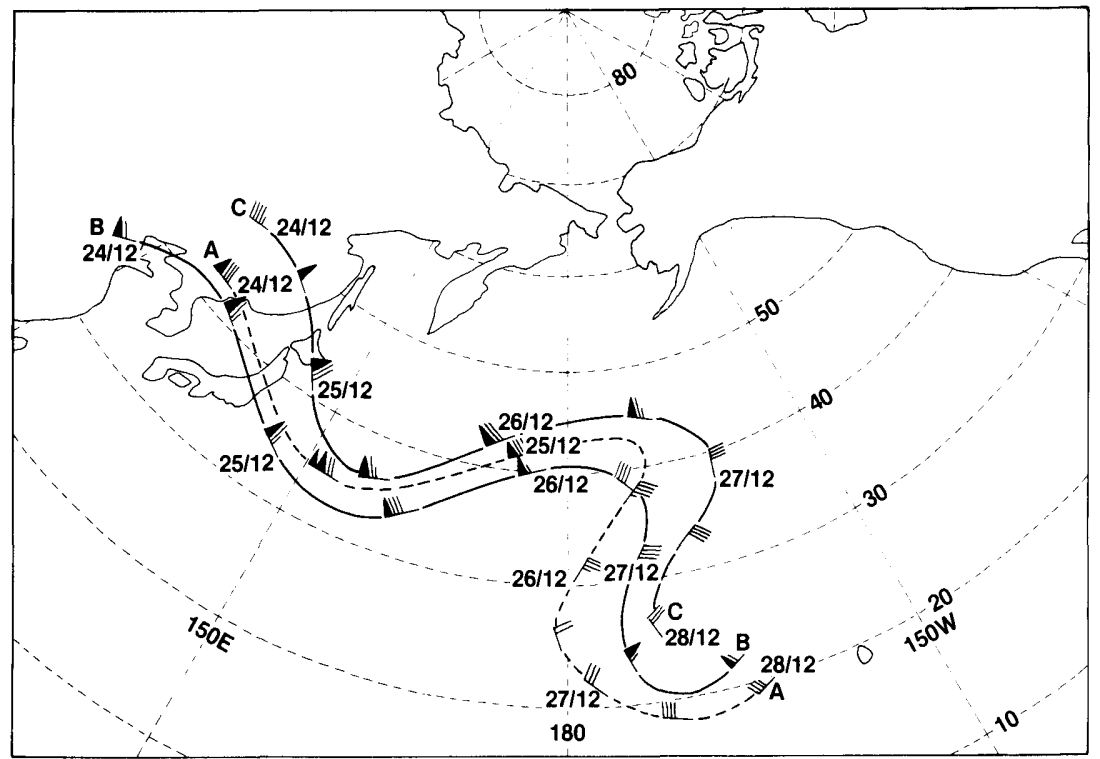

Fig. 3. Air mass trajectories constructed for the 28 July flight.

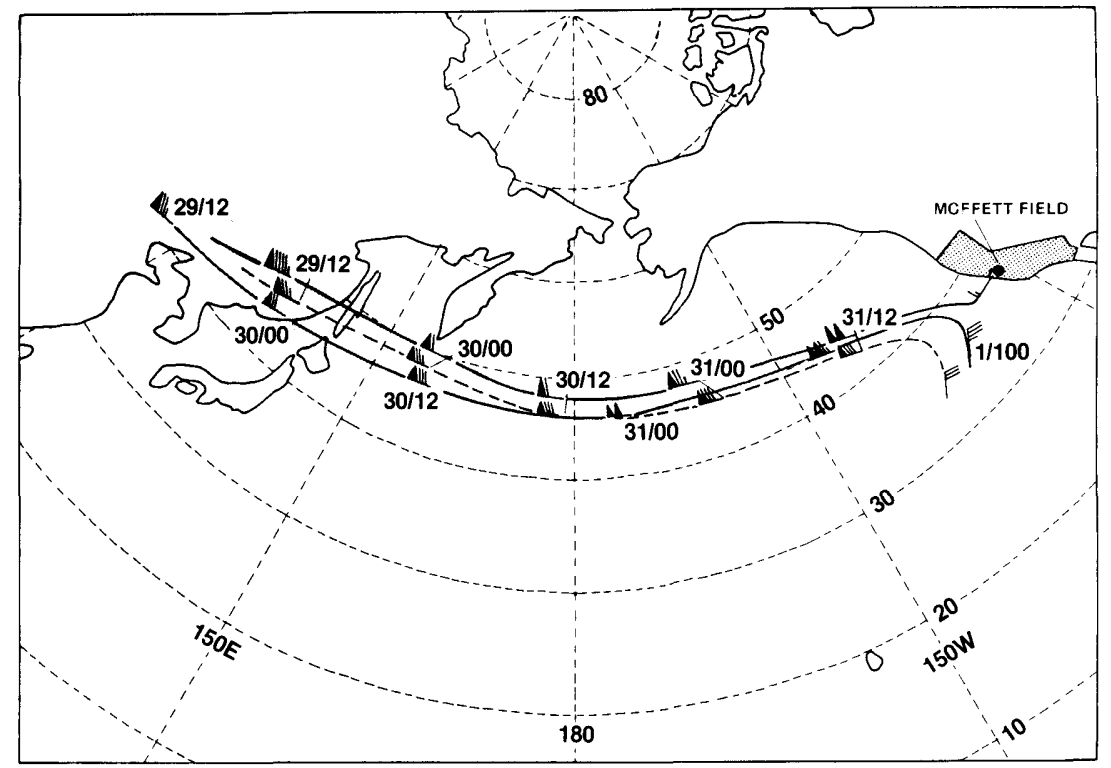

Fig. 4. Air mass trajectories constructed for the 31 July flight.

The trajectories constructed for the 28 July flight (Fig. 3) begin at 1200 GMT on 24 July, and end 4 days later to the northwest of Hawaii. They are accompanied by 4 of the $\psi_{m}$ analyses (Figs. $5 \mathrm{a}-\mathrm{d}$ ) used to construct them. (A total of 22 analyses were prepared, at $12-\mathrm{h}$ intervals, for the period 22 July-1 August. To save space, only those needed for the present discussion are reproduced here.)

The trajectories constructed for the 31 July

Tellus 42B (1990), 1 

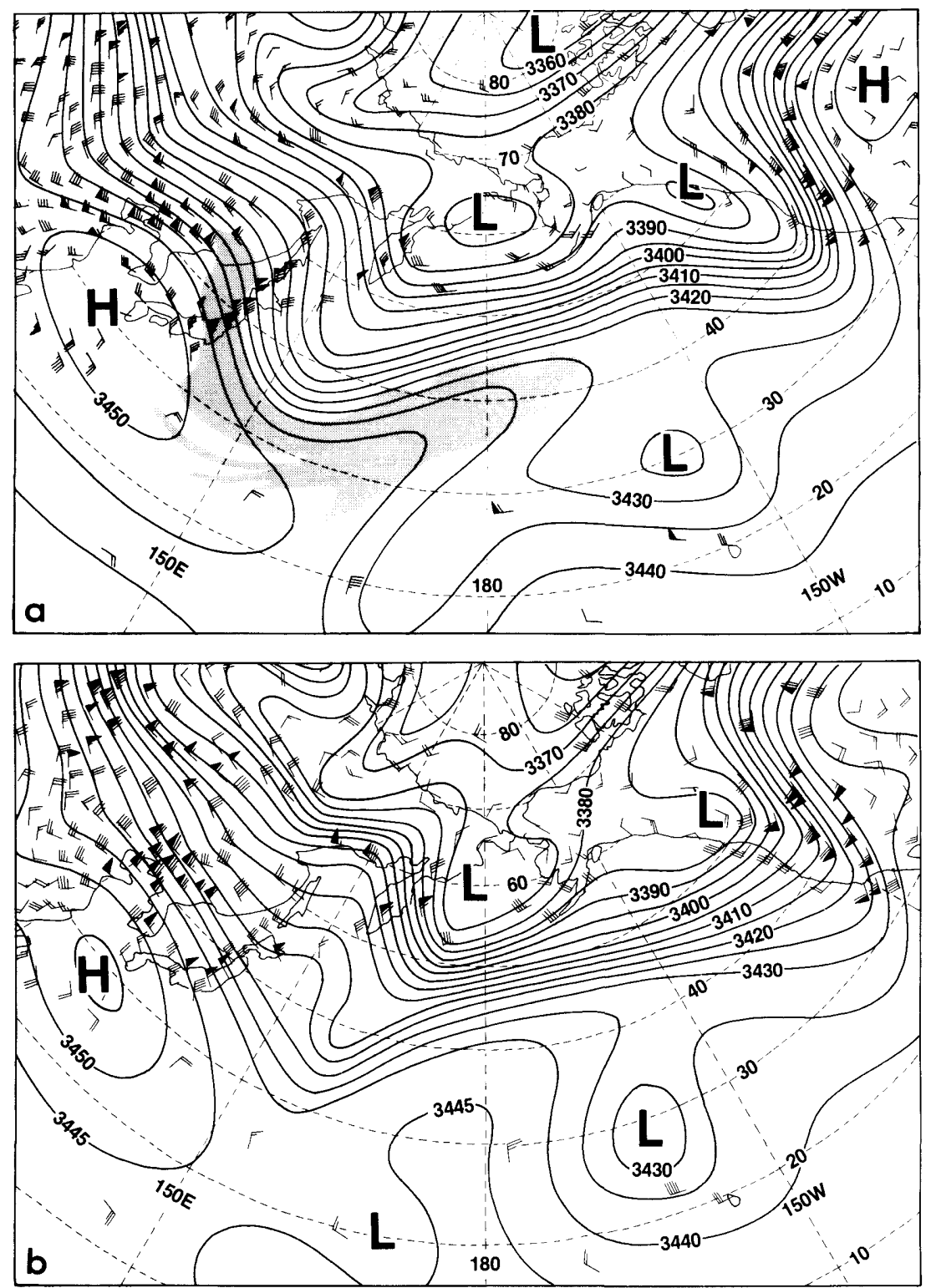

Fig. 5. Four of the Montgomery stream function analyses used to construct trajectories for the 28 July flight. Units are $100 \mathrm{~m}^{2} \mathrm{~s}^{2}$, and contour intervals $500 \mathrm{~m}^{2} \mathrm{~s}^{2}$. Wind indications conform to the standard convention, with each full barb corresponding to $5 \mathrm{~m} \mathrm{~s}^{-1}$ (10 knots), and a pennant to $25 \mathrm{~m} \mathrm{~s}^{-1}$ (50 knots): (a) 1200 GMT, $25 \mathrm{July} 1983$; (b) 1200 GMT, 26 July 1983; (c) 1200 GMT, 27 July 1983; (d) 1200 GMT, 28 July 1983.

flight (Fig. 4) begin at 1200 GMT on 29 July, and end several hundred kilometers off the California coast, at $0000 \mathrm{GMT}, 1$ August. Three of the $\psi_{m}$ analyses used to construct these trajectories appear as Figs. 6a-c.
The trajectories originating over the eastern Asiatic continent at 1200 GMT 24 July (Fig. 3) oscillate about $40^{\circ} \mathrm{N}$ to the west of the dateline, with two reversals in the sign of their curvature as the air moves eastward more rapidly than the 

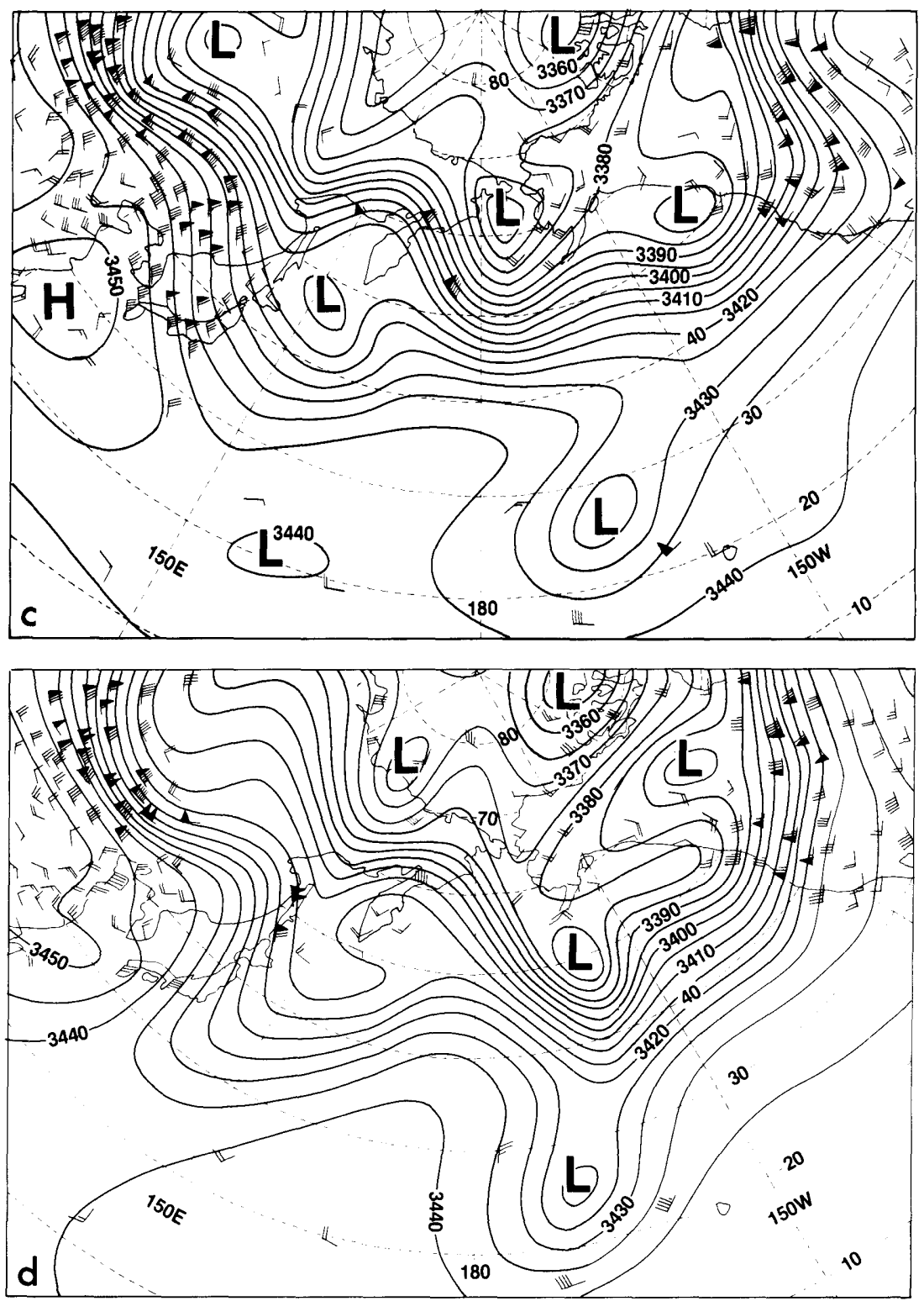

Fig. 5 (cont'd)

ridge-trough-ridge patterns. East of the dateline the large negative curvature accelerations and speed decelerations carry the air southward and westward into the influence region of a westward propagating and intensifying cyclonic vortex, a closed low in the $\psi_{m}$ analyses.
The increasing centripetal force produced by the increasing $\psi_{m}$ gradient then turns the air cyclonically and increases the speed of the parcels $A$ and B. A westward or southwestward propogation of mid-Pacific cut-off lows is common, especially during the summer and fall 

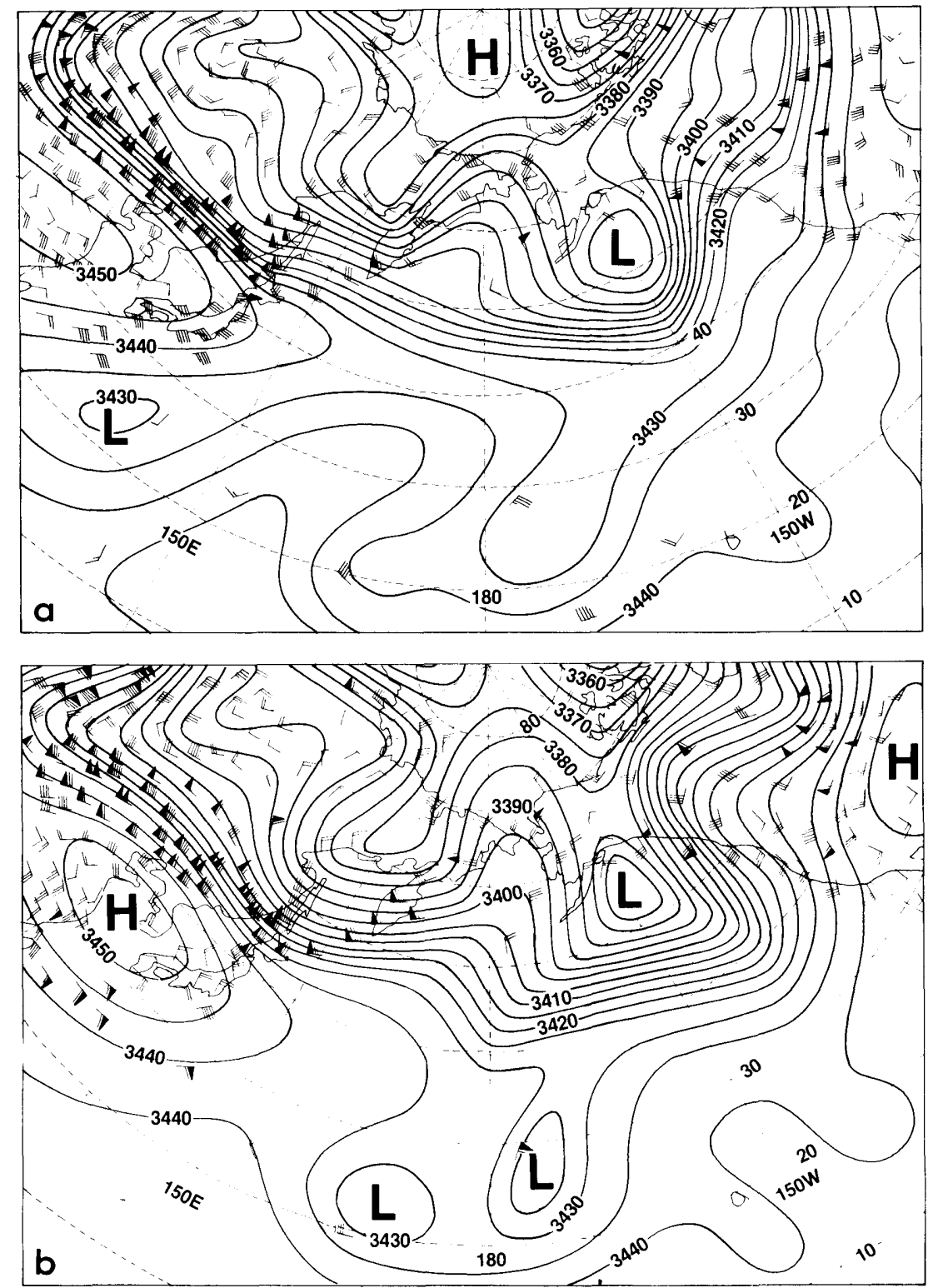

Fig. 6. Three of the Montgomery stream function analyses used to construct trajectories for the 31 July flight: (a) 0000 GMT, 30 July 1983; (b) 0000 GMT, 31 July 1983; 0000 GMT, 1 August 1983.

seasons; hence sudden latitudinal displacements such as the one from $40^{\circ} \mathrm{N}$ to $20^{\circ} \mathrm{N}$ exhibited by these trajectories are common also.

At 1200 GMT 24 July, parcels A and B were located in a band of cold upper tropospheric clouds, while parcel $\mathrm{C}$ was in clear air to the north of the cloud band, on the cyclonic side of an upper level jet. This same cloud band, now advecting off the continent, is toned grey in the analysis of Fig. 5a. Referring to the trajectories in Fig. 3 and comparing the 1200 GMT 25 July positions, one finds that $\mathrm{A}$ and $\mathrm{B}$ are in the cloud 


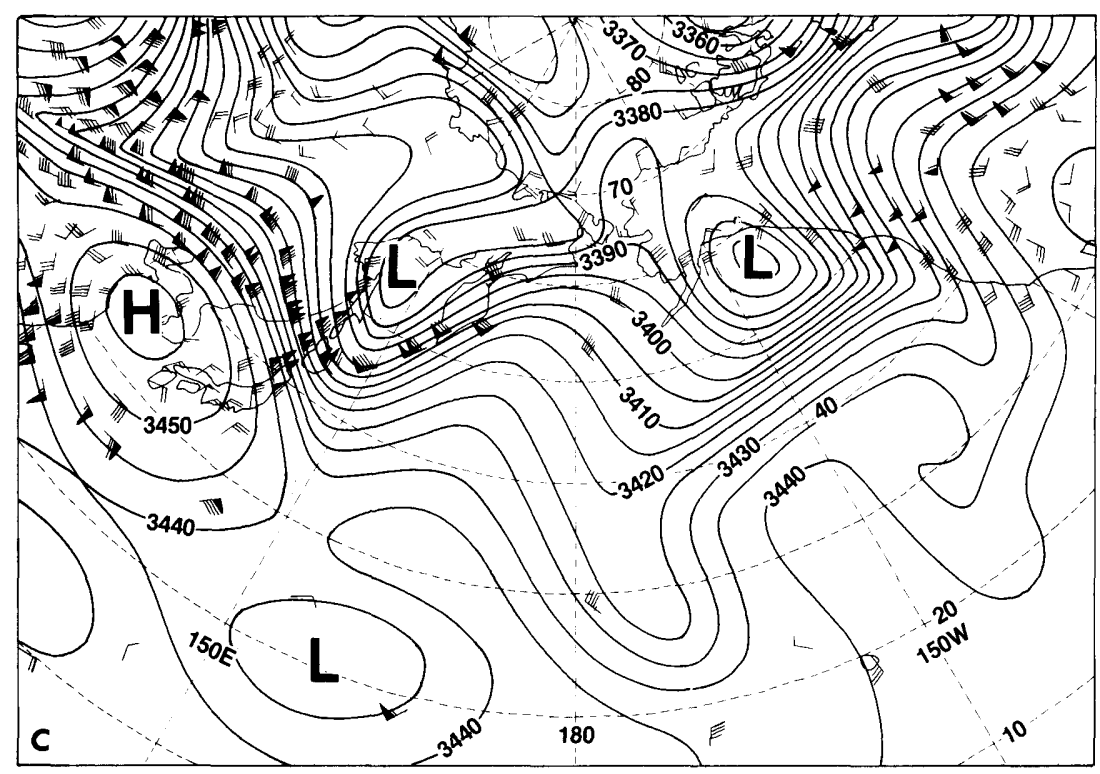

Fig. 6 (cont'd)

band, while $\mathrm{C}$, once again, is to the north of the band in cloudless air.

When the air turns anticyclonically, east of the dateline, the associated descent and compressional warming evaporates the clouds, but the contrast between the moist and dry air was still clearly visible in the GOES-West $6.7 \mu$ water vapor emission pictures. At 1200 GMT $28 \mathrm{July}$, parcel $\mathrm{C}$ was located on the cyclonic side of the jet (Fig. 5d), in dry air. Thus, both its position relative to the vortex center and its trajectory from the cyclonic side of the jet over the Asian mainland are consistent with a stratospheric rather than a tropospheric origin.

In this context, it is relevant to note that the zonal-monthly mean position of the $350 \mathrm{~K} \theta$ surface spans the upper troposphere from the equator to the mean position of the westerly jet $\left(40^{\circ} \mathrm{N}\right.$ to $45^{\circ} \mathrm{N}$ and $\left.\sim 200 \mathrm{mb}\right)$, and is in the stratosphere between the jet axis and the pole. Therefore, statistically, the mean jet separates tropospheric $350 \mathrm{~K}$ air south of the jet from stratospheric $350 \mathrm{~K}$ air north of the jet.

As the $\psi_{m}$ analyses of Figs. 5a-d suggest however, the zonal-monthly jet is a mathematical residual of an oscillating, sometimes splitting, sometimes merging, nonsteady jet (or jets.) When a jet splits, or bifurcates, it continues to separate air of different origins, as does the mean jet. For example, in an experiment conducted near Hawaii in November, 1983 (Danielsen et al., 1987 ) in which an aircraft traversed the jet at $350 \mathrm{~K}$, tracers characteristic of the troposphere (CO and water vapor) were enriched on the southern (anticyclonic) side of the jet, while tracers characteristic of the stratosphere (ozone and nitric oxide) were enriched on the cyclonic side.

The trajectories derived for the observations of 31 July (shown in Fig. 4) are remarkably similar to those one might deduce from the zonalmonthly mean charts for July, until the air approaches the west coast of North America. Moving rapidly eastward between $40^{\circ} \mathrm{N}$ and $45^{\circ} \mathrm{N}$, the air parcels cross the Pacific in just over two days. Then, as the parcels approach an amplifying north-south trough, the $\psi_{m}$ gradient weakens and the flow becomes increasingly supergeostrophic, turning anticyclonically with rapidly decreasing speeds. The loss in kinetic energy is compensated by an increase in the sum of potential energy and enthalpy; i.e., by an increase in $\psi_{m}$ (Danielsen, 1961; 1974). 
Because of the sparsity of meteorological observations in the western Pacific, this description based on the trajectory computations may be difficult to accept. However, Fig. 6c includes another example of this behavior, occurring in a data rich region. There is a similar sharp trough in the upper left corner of the figure, behind which the $\psi_{m}$ contours diverge and the observed flow is strongly difluent. Streamlines (lines parallel to the local flow) systematically cross $\psi_{m}$ contours towards larger $\psi_{m}$ values, while speeds decrease from $50+$ to $12-15 \mathrm{~m} \mathrm{~s}^{-1}(100+$ to $25-$ 30 knots). The conversion of energy is explicitly obvious; indeed, the air must decelerate to slow speeds before it can be turned cyclonically and pass the trough.

Two days earlier, on $30 \mathrm{July,} \mathrm{(Fig.} \mathrm{6a)} \mathrm{the} \psi_{m}$ gradient was strong enough to turn the air cyclonically at speeds of $25 \mathrm{~m} \mathrm{~s}^{-1}$. However, as the difluent flow developed over the next 24 and $48 \mathrm{~h}$, the trough sharpened and was extended southwestward, while the $\psi_{m}$ gradient in the trough weakened. (In effect the trough corresponds to the axis of dilation of a strong deformation, acting to extend the trough.) This same sequence of events is also seen in the trough approaching the western coast of North America in Fig. 6c.

These examples illustrate the importance of incorporating speed as well as curvature variations into trajectory computations. Because of the paucity of data, we do not claim that the trajectories presented in Figs. 3 and 4 are unambiguous. Nevertheless, the trajectories are dynamically consistent with the $\psi_{m}$ fields, which in turn are consistent with the satellite and radiosonde observations.

\section{Discussion}

The upper tropospheric radon concentrations observed during the 28 and 31 July flights (and, for that matter, the entire series of upper tropospheric radon concentration measurements presented here) did not show the expected behavior. Instead of the low (1-2 $\mathrm{pCi} / \mathrm{SCM})$ and relatively invariant concentrations expected, the actual radon concentrations were found to be extremely variable in space and time, with both mean and maximum values considerably greater than what had been expected on the basis of the limited number of upper tropospheric measurements available prior to this work.

The trajectory analyses presented in the preceeding section showed that the air sampled at altitude on 28 and 31 July with the highest radon concentrations had been located in the upper troposphere over Asia some two to four days earlier. In those analyses it also was seen that the rapid eastward transport occurred in regions where cold cirrus clouds were present in the satellite infrared photographs. The implication of these results is that radon-rich near-surface air was transported upward with the water vapor that produced these clouds.

The most probable form of vertical transport in this situation is within cumulonimbus updrafts originating in the boundary layer where both radon and water vapor concentrations are large. In large cumulonimbus clouds such near-surface air can reach the upper troposphere in less than an hour (e.g., Newton, 1966). Since radon, a noble gas, is not significantly scavenged by precipitation, and radioactive decay during the rapid ascent would be negligible, dilution with entrained environmental air was probably the dominant factor reducing radon concentrations during this phase of the transport.

The hypothesis that thunderstorms over continental Asia provided the rapid vertical ascent was tested by examining the Nimbus 7 satellite observations and the 0000 GMT and 1200 GMT surface weather observations for 24 and $29 \mathrm{July}$, the dates when the trajectories passed over northeastern China.

On the 24th, the satellite photos (visible and infrared) showed two bands of convective storms oriented NE-SW over eastern China. Numerous surface observations of thunderstorms, lightning and cumulonimbus clouds with cirrus anvils confirm that these lines, particularly the eastern line, included major continental convective storms capable of transporting radon-rich surface level air to the upper troposphere. The eastern line, oriented from $30^{\circ} \mathrm{N} / 113^{\circ} \mathrm{E}$ to $40^{\circ} \mathrm{N} / 120^{\circ} \mathrm{E}$ at 0000 GMT on the 24th, intensified during the day as it moved eastward by about 5 degrees of longitude during the period 0000-1200 GMT. The fact that the thunderstorms were organized in lines is consistent with surface convergence being the probable initiation mechanism.

Another line of convective activity over 
northeastern China was evident in the Nimbus 7 satellite observations and confirmed by thunderstorm observations on the 29th. In this case the line of activity extended from $30^{\circ} \mathrm{N} / 100^{\circ} \mathrm{E}$, through $35^{\circ} \mathrm{N} / 115^{\circ} \mathrm{E}$, and terminated at $45^{\circ} \mathrm{N} / 13^{\circ} \mathrm{E}$.

Thus, in both instances active thunderstorms were within the probable trajectory source regions determined for the high radon concentrations observed near Hawaii and over the eastern Pacific on 28 and 31 July.

If the reduction in the initial boundary-layer radon concentration during the ascent (due to entrainment of radon-poor tropospheric air) is taken to be on the order of $50 \%$ (Danielsen, 1977), and further reductions during the eastward transport from mixing with upper tropospheric air and from radioactive decay during a 3-day transit are estimated to be of the order of $50 \%$ and $40 \%$ respectively, this would result in a nominal overall reduction in radon concentration

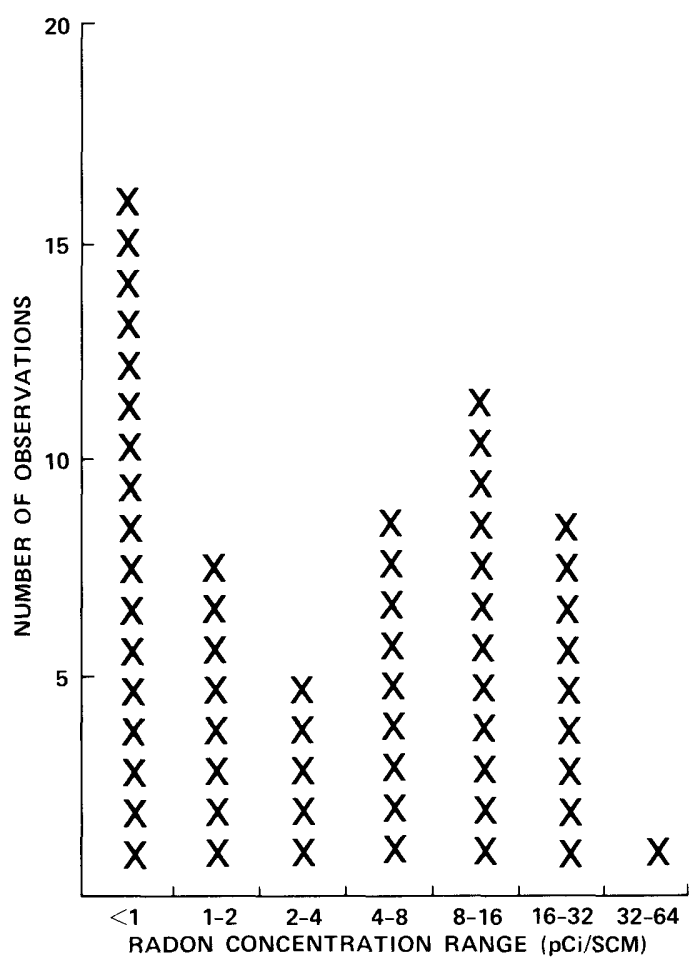

Fig. 7. Frequency distribution plot of the 61 radon measurements. to about $15 \%$ of the original, near-surface value. Radon concentrations in the continental boundary layer are typically on the order of $100-300$ pCi/SCM (Cox et al., 1970; Lambert et al., 1982; Liu et al., 1984). Higher concentrations are frequently observed however, particularly in the morning hours (Gold et al., 1964), and at the downwind edges of continents (Turekian et al., 1977). Thus, the transport processes discussed here are not inconsistent with the elevated radon concentrations observed during the 1983 and 1984 flight series, including the exceptional 40 $\mathrm{pCi} / \mathrm{SCM}$ value observed on 28 July.

Considering the data set as a whole, it is clear that the elevated radon concentrations observed on 28 and 31 July were not an isolated phenomenon. However, while the mean of the 64 measurements, $7.5 \mathrm{pCi} / \mathrm{SCM}$ is significantly higher than the 1-2 $\mathrm{pCi} / \mathrm{SCM}$ values thought typical of the upper troposphere, a more striking pattern is seen if the individual observations are plotted as a frequency distribution, as has been done in Fig. 7. The observations have a distinctly bimodal distribution, with approximately $\frac{2}{5}$ of the observations falling close to $1 \mathrm{pCi} / \mathrm{SCM}$, and $\frac{3}{5}$ falling in a high concentration mode centered at about $11 \mathrm{pCi} / \mathrm{SCM}$. This pattern is inconsistent with that which would be observed if turbulent mixing were the dominant means of radon vertical transport, but is consistent with the thesis that most of the radon observed in this series of measurements was carried aloft by localized vertical convection.

Because of its near-surface source and rapid transport, the radon-rich upper tropospheric air observed in this study was almost certainly enriched in other continentally-derived trace constituents as well, particularly those not removed by precipitation scavenging, and with free tropospheric lifetimes on the order of a few weeks. Thus our findings would be consistent with Ehhalt et al.'s (1985) attribution of some of the elevated light hydrocarbon concentrations they observed in the upper troposphere during the STRATOZ II experiment to ascent in localized convective cells. In this regard, both our observations and those of Ehhalt et al. appear to be consistent with the Walker circulation effects postulated by Newell et al. (1988).

Finally, we would refer those interested in long-range transports across the Pacific to the 
extensive body of knowledge generated in the SEAREX program, e.g., Duce et al. (1982), Uematsu et al. (1983) and Merrill et al. (1985).

\section{Acknowledgements}

We wish to thank Louis Haughney, Carl Gillespie and Jim McClenahan of the Kuiper Airborne Observatory Project Office for facilitating the installation and operation of our equipment aboard the aircraft. The isokinetic sampling inlet was provided through the courtesy of Henri
Leblond and Badin-Crouzet SA. Satellite images and Asian surface level synoptic charts were kindly provided by Michael McDermott of the Naval Postgraduate School. The radon gas calibration was carried out in cooperation with Kenneth Bruland and Ross Williams of the Marine Sciences Program, University of California at Santa Cruz. This work was supported by the National Aeronautics and Space Agency Consortium Agreement NCA2-167, National Science Foundation Grant INT-8313493, and by the CNRS (ATP Atmosphere Moyenne). CFR contribution 1057.

\section{REFERENCES}

Andreae, M. O., Berresheim, H., Andreae, T. W., Kritz, M. A., Bates T. S. and Merrill, J. T. 1988. Vertical distribution of dimethylsulfide, sulfur dioxide, aerosol ions, and radon over the northeast Pacific Ocean. J. Atmos. Chem. 6, 149-173.

Broecker, W. E. and Peng, T.-H. 1971. The vertical distribution of radon in the BOMEX area. Earth and Planet. Sci. Lett. 11, 99-108.

Cox, W. M., Blanchard, R. L. and Kahn, B. 1970. Relation of radon concentration in the atmosphere to total moisture detention in soil and atmospheric thermal stability. In: Radionuclides in the environment (ed. R. F. Gould). Advances in Chemistry Series, 93. Washington, D.C.: American Chemical Society, 436-446.

Danielsen, E. F. 1959. The laminar structure of the atmosphere and its relation to the concept of the tropopause. Arch. Meteorol. Geophys. Bioklimatol. Ser. B11, 293-332.

Danielsen, E. F. 1961. Trajectories: isobaric, isentropic and actual. J. Meteorol. 18, 479-486.

Danielsen, E. F. 1974. Review of trajectory methods. In: Adv. Geophys., vol. 18B. New York: Academic Press, 73-94.

Danielsen, E. F. 1977. Inherent difficulties in hail probability prediction. In: Hail: $A$ review of hail science and hail supression, Meteor. Monogr., no. 38 (eds. G. B. Foote and C. A. Knight). Amer. Meteor. Soc., 135-143.

Danielsen, E. F. 1980. Stratospheric source for unexpectedly large values of ozone measured over the Pacific Ocean during Gametag, August, 1977. J. Geophys. Res. 85, 401-412.

Danielsen, E. F., Gaines, S. E., Hipskind, S., Gregory, G. L., Sachse, G. W. and Hill, G. F. 1987. Meteorological context for Fall [GTE] experiments including distributions of water vapor, ozone and carbon monoxide, J. Geophys. Res. 92, 1986-1994.

Dickerson, R. R., Huffman, G. J., Luke, W. T., Nunnermacker, L. J., Pickering, K. E., Leslie,
A. C. D., Lindsey, C. GF., Slinn, W. G. N., Kelly, T. J., Daum, P. H., Delany, A. C., Greenberg, J. P., Zimmerman, P. R., Boatman, J. F., Ray, J. D. and Stedman, D. H. 1987. Thunderstorms: an important mechanism in the transport of air pollutants. Science $235,460-465$.

Duce, R. A., Unni, C. K., Ray, B. J., Prospero, J. M. and Merrill, J. T. 1980. Long-range atmospheric transport of soil dust from Asia to the tropical North Pacific: Temporal variability. Science 209, 15221524.

Ehhalt, D. H., Rudolph, J., Meixner, F. and Schmidt, U. 1985. Measurements of selected C2-C5 hydrocarbons in the background troposphere: vertical and latitudinal variations. J. Atmos. Chem. 3, 29-52.

Evans, R. D. 1955. The atomic nucleus. New York: McGraw-Hill, 972 pp.

Gidel, L. 1983. Cumulus cloud transport of transient tracers. J. Geophys. Res. 88, 6587-6599.

Gold, S., Barkhau, H. W., Shleien, B. and Kahn, B. 1964. Measurement of naturally occurring radionuclides in air. In: The natural radiation environment (eds. J. A. S. Adams and W. M. Lowder). Chicago: Univ. Press, 369-382.

Jacobi, W. and Andre, K. 1963. The vertical distribution of Radon-222, Radon-220 and their decay products in the atmosphere. J. Geophys. Res. 68 , 3799-3814.

Jegou, A. 1983. Optimisation d'un appareillage de mesure du radon 222 dans la haute troposphere et la basse stratosphere, Memoire Diplome Ingenieur, Conservatoire National des Arts et Metiers, Paris.

Kritz, M. A. 1975. An advective hypothesis for the origin of the stratospheric aerosol layer. $J$. de Physique 36, C8-17.

Lambert, G., Polian, G., Sanak, J., Ardouin, B., Buisson, A., Jegou, A. and Le Roulley, J. C. 1982. Cycle du radon et de ses descendants: application a l'etude des echanges troposphere-stratosphere. Ann. Geophys. 38, 497-531. 
Larson, R. E. 1973. Measurements of radioactive aerosols using thin plastic scintillators. Nucl. Instr. and Meth. 108, 467-470.

Larson, R. E. 1978. Radon-222 measurements during marine fog events off Nova Scotia. J. Geophys. Res. $83,415-418$.

Larson, R. E., Lamontagne, R. A., Wilkness, P. E. and Wittmann, W. I. 1972. Radon-222, CO, CH4 and continental dust over the Greenland and Norwegian Seas. Nature 240, 345-347.

Liu, S. C., McAfee, J. R. and Cicerone, R. J. 1984. Radon 222 and tropospheric vertical transport. $J$. Geophys. Res. 89, 7291-7297.

Merrill, J. T., Bleck, R. and Avila, L. 1985. Modelling atmospheric transport to the Marshall Islands. $J$. Geophys. Res. 90, 12,927-12,936.

Moore, H. E., Poet, S. E. and Martell, E. A. 1973. $\mathrm{Rn}-222, \mathrm{~Pb}-210, \mathrm{Bi}-210$ and $\mathrm{Po}-210$ profiles and aerosol residence times versus altitude. J. Geophys. Res. 78, 7065-7075.

Newell, R. E., Shipley, S. T., Connors, V. S. and Reichle, H. G. Jr. 1988. Regional studies of potential carbon monoxide sources based on space shuttle and aircraft measurements. J. Atmos. Chem. 6, 61-82.

Newton, C. W. 1966. Circulations in large sheared cumulonimbus. Tellus 18, 699-722.

Polian, G. 1984. Les transports atmospheriques dans l'hemisphere sud, et le bilan global du radon 222 . Thèse de docteur de l'Universite, Universite Pierre et Marie Curie, Paris.
Polian, G., Lambert, G., Ardouin, B. and Jegou, A. 1986. Longrange transport of continental radon in subantarctic and antarctic regions. Tellus $38 B, 178$ 189.

Prospero, J. M. and Carlson, T. N. 1970. Radon-222 in the North Atlantic trade winds: relationship to dust transport from Africa. Science 167, 974-977.

Uematsu, M., Duce, R. A., Prospero, J. M., Chen, L., Merrill, J. T. and McDonald, R. L. 1983. Transport of mineral aerosol from Asia over the North Pacific Ocean. J. Geophys. Res. 88, 5343-5352.

Turekian, K. K., Nozaki, Y. and Benninger, L. K. 1977. Geochemistry of atmospheric radon and radon products. Ann. Rev. Earth Planet. Sci. 5, 227-255.

Wexler, H., Machta, L., Pack, D. H. and White, F. D. 1956. Atomic energy and meteorology. Proc. 1st Int. Conf. Peaceful Uses At. Energy (1955), 13, 333.

Wilkening, M. H. 1970 . Radon 222 concentrations in the convective patterns of a mountain environment. J. Geophys. Res. 75, 1733-1740.

Wilkness, P. E., Lamontagne, R. A., Larson, R. E., Swinnerton, J. W., Dickerson, C. B. and Thompson, T. 1973. Atmospheric Trace Gases in the Southern Hemisphere. Nature Phys. Sci. 245, 45-47.

Wilkness, P. E. and Larson, R. E. 1984. Atmospheric radon measurements in the Arctic; fronts, seasonal observations and transport of continental air to polar regions. J. Atmos. Sci. 41, 2347-2358. 